\title{
Expression of Myoglobin in the Urine of Cocaine Users
}

\author{
Marie M. Bourgeois, Ira S. Richards
}

Environmental and Occupational Health, University of South Florida College of Public Health, Tampa, USA.

Email: mbourgeo@health.usf.edu

Received January $15^{\text {th }}, 2013$; revised March $7^{\text {th }}, 2013$; accepted April $11^{\text {th }}, 2013$

Copyright (C) 2013 Marie M. Bourgeois, Ira S. Richards. This is an open access article distributed under the Creative Commons Attribution License, which permits unrestricted use, distribution, and reproduction in any medium, provided the original work is properly cited.

\begin{abstract}
Background: The possibility exists that cocaine use in the absence of frank clinical presentation of acute cardiac events may be associated with subclinical injury including the release of myoglobin which is a nonspecific marker for cardiac and skeletal muscle damage. Objectives: This investigation examined urine specimens for potential differences between cocaine use and the expression of myoglobin (a marker associated with cardiovascular damage, inflammation and oxidative stress). Methods: 40 urine specimens were assayed for cocaine metabolites, creatinine, total protein (BSA) and myoglobin using ELISA and colorimetry. Results: We observed significant differences between male control and male cocaine positive urines for myoglobin. Interestingly, there was no statistically significant difference in females between control and cocaine positive urines. Conclusion: Differences in the urinary expression of myoglobin may be important in evaluating the gender based effects of cocaine use and may have potential clinical applications which may be related to gender differences in signs and symptoms of cocaine toxicity.
\end{abstract}

Keywords: Cocaine; Myoglobin; Gender; Urine

\section{Introduction}

Cocaine (benzoylmethylecgonine) is an alkaloid derived from the leaves of Erthroxylon coca, a shrub indigenous to South America [1]. Despite restrictions on importation and distribution, cocaine has become one of the most commonly used illicit drugs. In 2006, The Substance Abuse and Mental Health Administration (SAMSHA) reported more than six million Americans ages 12 and older had used one or more forms of cocaine in the previous year [2]. Cocaine is the most frequently reported illicit drug associated with emergency department (ED) admissions [3].

Cocaine is a powerful sympathomimetic capable of vasoconstriction and increasing heart rate, blood pressure, contractility, respiration, myocardial oxygen demand and body temperature [4]. Cocaine use is linked to atherosclerosis, myocardial ischemia, myocardial contraction band formation and sudden death [5]. The vasoconstriction associated with cocaine usage is thought to result from its blockade of norepinephrine and dopamine reuptake at preganglionic sympathetic nerve endings; the extended catecholamine presence increases heart rate and blood pressure [6]. Hypertension is associated with disruptions in endothelial cell function and oxidative stress.
Myoglobin from myolysis, common with syndromes like rhabdomyolysis, may cause oxidative stress [7].

Cocaine-induced chest pain is the most common symptom reported by emergency department patients and is likely due to myocardial ischemia $[6,8]$. The rate of cocaine use is almost twice as high in males when compared to females; however, SAMSHA statistics indicate males and females have comparable rates of cocaine related emergency department visits [9]. Significant gender dimorphism has been documented in cardiovascular and other diseases. Higher male susceptibility to cardiovascular disease may be due to genetic, hormonal, or lifestyle factors or to a combination of mechanisms [10]. Gender differences in lifestyle risk factors (i.e. smoking, exercise and diet) for cardiovascular disease appear to contribute to the gender gap in cardiovascular disease; however, these lifestyle factors do not completely account for the dimorphism. Sex-based differences in the clinical presentation, diagnosis, and treatment outcomes of cardiac disease have long been recognized. Despite the fact that men suffer from higher rates of cardiovascular disease, the total number of deaths from cardiovascular disease has been higher for women than for men [11]. Up to one quarter of AMIs in patients under the age of 45 are associated with cocaine use [4]. Some of these patients ex- 
hibited elevated CK-MB levels or electrocardiogram (ECG) changes consistent with acute myocardial infarction (AMI); however, the majority reported recurrent chest pain subsequent to cocaine use following discharge [12].

Cocaine use has been linked to inflammation and oxidative stress and may result in the release of biomarkers into blood [13]. Oxidative stress has also been implicated as an early triggering event of cocaine-induced cardiomyopathy and atherosclerosis [13]. Cocaine use is also linked to cardiac and skeletal muscle dysfunction and rhabdomyolysis [1,14]. Cocaine induced hyperpyrexia may trigger rhabdomyolysis and therefore the possibility exists for the presence of elevated levels of myoglobin to be released. The rhabdomyolysis from acute cocaine intoxication has generally been associated with uncontrolled thermoregulation and acute cardiac crisis. An estimated $24 \%$ of cocaine users develop rhabdomyolysis [15].

The possibility exists that cocaine use in the absence of frank clinical presentation of acute cardiac events may be associated with subclinical injury including the release of myoglobin which is a nonspecific marker for cardiac and skeletal muscle damage. As most toxicological screens for illicit substances primarily utilize urine specimens, we examined the possibility of establishing a relationship between the expression of myoglobin and cocaine use [16]. As albuminuria, typically determined using an albumin/creatinine ratio, is considered a standard measure of kidney function, the urinary expression of total protein (BSA) was also examined.

\section{Materials and Methods}

This study was approved by the Institutional Review Board governing the policies and procedures for research involving human subjects. Male and female urine samples were assayed for cocaine metabolites, total protein (BSA), creatinine and myoglobin. Urine specimens were obtained from the Agency for Community Treatment and Services of Tampa (ACTS) and were tested at the university's toxicology Laboratories. Following enzyme multiplied immunoassay technique (EMIT) testing performed on an Olympus AU400e, specimens were further studied for biomarkers.

A modified 10 drug National Institute on Drug Abuse (NIDA) panel, which includes delta-9-tetrahydrocannabinol, opiates, amphetamines, barbiturates, cocaine, ethanol, benzodiazepines, propoxyphene, methadone and oxycodone, was used to screen urine samples. The inclusion criteria for this study required that specimens were negative for alcohol and all other illicit substances and adulteration according to standard drug screening methods for color, odor, creatinine concentration and specific gravity.
Creatinine was assayed according to standard methodology (Cayman Chemical Company, USA). The assay relies on Jaffe's reaction in which a yellow or orange color is formed when the metabolites are treated with alkaline picrate. The color of the creatinine is destroyed at acidic $\mathrm{pH}$. The difference in color intensity measured at $495 \mathrm{~nm}$ before and after acidification is proportional to the creatinine concentration. A creatinine standard curve was constructed for urine creatinine concentration determination.

Total protein (BSA for bovine serum albumin) was assayed using the Bradford method (Thermo Scientific Life Research Products, Rockford, IL). Briefly, in the acidic environment of the reagent, protein binds to the Coomassie dye. This results in a spectral shift from the reddish/brown form of the dye (absorbance maximum at $465 \mathrm{~nm}$ ) to the blue form of the dye (absorbance maximum at $610 \mathrm{~nm}$ ). The difference in optical density is measured at $595 \mathrm{~nm}$. The total protein concentration in the specimens was determined using a standard curve constructed from known values of albumin standards.

The Cocaine metabolite assay (ELISA kit-Immunalysis Corporation, Pomona, CA) is based upon the competitive binding to antibody of enzyme labeled antigen and unlabeled antigen, in proportion to their concentration in the reaction mixture. Briefly, a $10 \mu \mathrm{l}$ aliquot of urine diluted with phosphate buffered saline is incubated with a $100 \mu \mathrm{l}$ dilution of horseradish peroxidase labeled benzoylecgonine (BE) derivative in antibody coated microplate wells. The wells are then washed and the chromagen 3,3',5,5'-tetramethylbenzidine (TMB) is subsequently added. The color produced is stopped using $1 \mathrm{~N}$ hydrochloric acid stop solution and the wells read at 450 $\mathrm{nm}$ using a TECAN Infinite M200. The intensity of the color developed is inversely proportional to the concentration of drug in the sample.

Urine samples were considered to be positive for cocaine using standard forensic guidelines to establish positive and negative metabolite (BE) cutoff levels. The cocaine negative specimens contained less than $25 \mathrm{ng} / \mathrm{ml}$ $\mathrm{BE}$ urine, averaging $6 \mathrm{ng} / \mathrm{ml} \mathrm{BE}$. Anything above $25 \mathrm{ng} /$ $\mathrm{ml} \mathrm{BE}$ urine was considered positive for cocaine use; the cocaine positive urine specimens ranged from $40 \mathrm{ng} / \mathrm{ml}$ $\mathrm{BE}$ and higher.

Myoglobin was assessed using an ELISA kit (ALPCO Diagnostics, Salem, NH). Briefly, the samples were added to antibody coated microplates, incubated, washed with the kit-specific wash buffer, incubated in the presence of the chromagen TMB before the reaction was terminated with an acidic stop solution. The plate is then at $450 \mathrm{~nm}$.

A total of 40 urine specimens 20 cocaine metabolite negative (10 males and 10 females) and 20 cocaine meta- 
bolite positive (12 males and 8 females)] were analyzed. A Student's t test for significance (JMP Start Statistics, Release 4.0.4 SAS Institute, 2001) was used to compare biomarker concentration in the cocaine metabolite negative and cocaine metabolite positive specimens for male and female urine specimens. A p value of $<0.05$ was considered to be statistically significant.

\section{Results}

There were no statistically significant differences in either the myoglobin or the total protein concentrations in cocaine negative and cocaine positive female urine specimens (Figure 1).

A statistically significant difference $\left(p={ }^{+} 0.03\right)$ was observed in myoglobin concentrations of cocaine negative and cocaine positive male urine specimens; however, the differences in the total protein concentrations in cocaine negative and cocaine positive male urine specimens were not statistically significant (Figure 2).

Again, the mean concentration of myoglobin was significantly higher in male cocaine positive urine when compared to controls. This was not observed in females (Table 1).
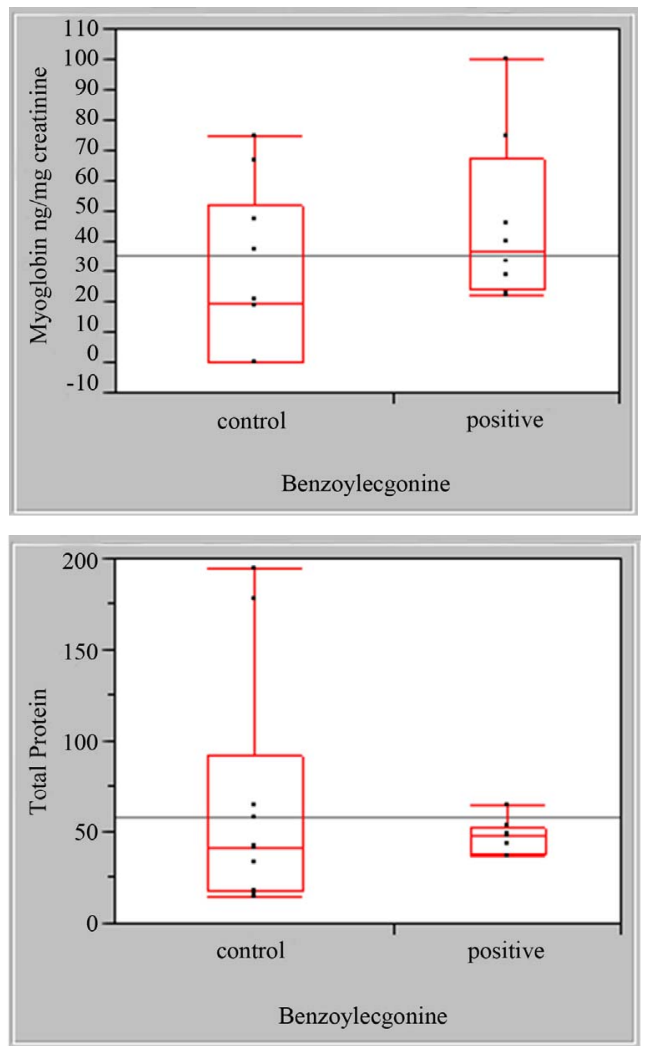

Figure 1. Female myoglobin and total protein boxplots, myoglobin standardized to $\mathrm{mg}$. Creatinine cocaine negative (control) and cocaine positive urine specimens, total protein (BSA) standardized to $\mathrm{mg}$. Creatinine cocaine negative (control) and cocaine positive urine specimens.
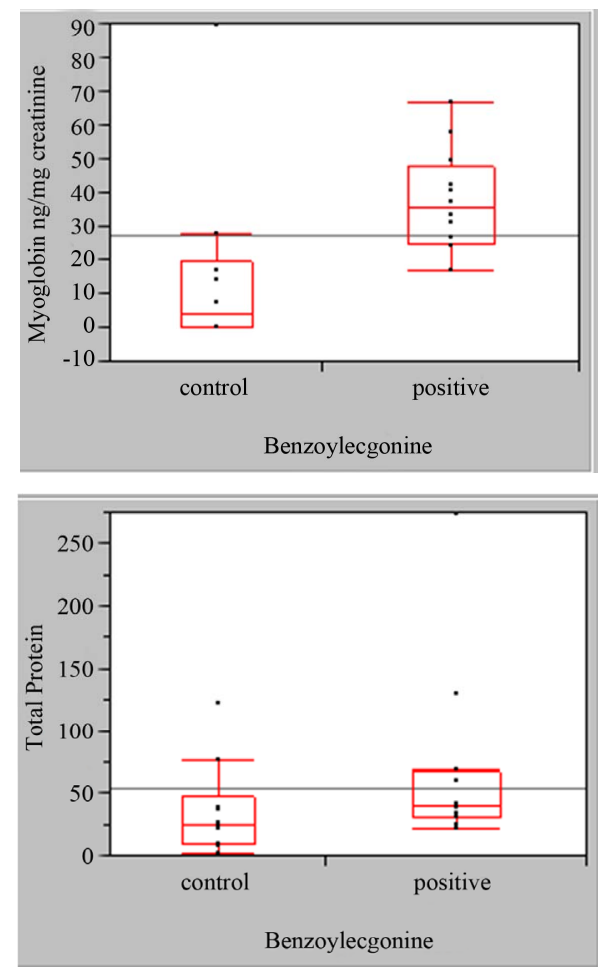

Figure 2. Male myoglobin and total protein boxplots, myoglobin standardized to $\mathrm{mg}$. Creatinine cocaine negative (control) and cocaine positive urine specimens, total protein (BSA) standardized to $\mathrm{mg}$.

\section{Discussion}

Cocaine is well absorbed mucosally in the oral cavity and the pulmonary system and metabolized almost immediately by serum cholinesterase $[17,18]$. Cocaine is also metabolized by hepatic carboxylesterases. The serum halflife of cocaine is less than an hour. The pharmocodynamics do not change substantially for different routes of entry despite differences in onset of action, peak absorbance and duration of effect. BE and ecgonine methyl ester (EME) are the primary metabolites. BE and EME have both been shown to elevate blood pressure [19].

Cocaine increases intracellular oxygen demand, elevates heart rate, arterial blood pressure and body temperature [20]. The dopaminergic action of cocaine is thought to contribute to cocaine-induced hyperthermia; cocaine inhibits the reuptake of dopamine by downregulating D2 receptor activity in the hypothalamus [17,21]. D2 receptors are involved with processes that decrease core body temperature. Hyperthermia may also result from excessive muscular activity coupled with warm ambient temperature and high [22]. Left untreated, hyperthermia can lead to rhabdomyolysis [22]. The mortality rate among patients with cocaine induced rhabdomyolysis syndrome is quite high and, in large measure, is the result of hyperexia [23]. Rhabdomyolysis is characterized by myolysis and the subsequent release of cellular con- 
Table 1. Male and female control and cocaine positive urine specimens.

\begin{tabular}{ccccccc} 
Assay & \multicolumn{3}{c}{ Male } & \multicolumn{3}{c}{ Female } \\
\cline { 2 - 7 } & Control & Cocaine Positive & $\mathbf{p}$ & Control & Cocaine Positive & p \\
\hline & $(\mathbf{n}=\mathbf{1 0})$ & $(\mathbf{n = 1 2 )}$ & & $(\mathbf{n}=\mathbf{1 0})$ & $\mathbf{( n = 8 )}$ & 0.44 \\
\hline${ }^{*}$ Total Protein $[\mathrm{pg}]$ & $32.2 \pm 12.1$ & $66.7 \pm 22.4$ & 0.24 & $65.9 \pm 20.8$ & $47.4 \pm 3.2$ & $45.9 \pm 9.8$
\end{tabular}

All values are expressed as mean \pm standard error of the mean $(\mathrm{SEM}) ;{ }^{*}$ values standardized per $\mathrm{mg}$ creatinine; ${ }^{+}$significant at $\mathrm{p}<0.05$.

tents, particularly myoglobin. Abnormal levels of myoglobin typically are released within 2 to 4 hours of significant myocardial or skeletal muscle injury [24,25]. Levels peak 6 to 12 hours following the pathophysiologic event; returning to normal levels within 36 hours. Myoglobin is a general marker of cardiac and skeletal muscle derangement; elevated levels are considered suggestive of cardiovascular, skeletal muscle or other damage, particularly in the presence of confirmatory symptomatology.

\section{Limitations}

Our study has several limitations. The blinded specimens provided by ACTS did not provide information on age, medical history or substance abuse habits of the donor. The absence of this information could skew the results, particularly if the donor had underlying chronic diseases such as diabetes, cardiac or renal pathology, or diminished nutritional status. While the urine specimens in the study were not obviously cloudy, discolored or strongsmelling, all of which may be suggestive of a urinary tract infection; the possibility exists that female specimen donors may have been suffering from a subclinical urinary tract infection. Such infections may impact the urinary expression of markers associated with inflammation. Finally, examinations of myoglobin and total protein in urine have been based almost exclusively on timed urine collections. The urines collected by ACTS were spot urines with an undetermined volume.

\section{Conclusion}

The data suggest that there were gender based differences between control and experimental urine means for myoglobin. There were no statistically significant results for total protein. The increased level of myoglobin observed in male cocaine positive urine may result from either a direct effect of cocaine on muscle or may be secondary to elevation of core body temperature. It may be related to a greater muscle mass in male subjects in general when compared to females. Our results further suggest that myoglobin may potentially be a useful prognostic indicator of subclinical pathological changes associ- ated with the use of cocaine. We currently do not know the mechanism underlying our observations. While we recognize the limitations of our study, the results suggest that differences in the expression of myoglobin may be an important noninvasive way to assess cocaine induced injury. A prospective study is deemed to be further necessary to obtain demographic data and medical backgrounds of study participants that we were blinded to in this pilot study so that the pathophysiological mechanisms that may be occurring can be more clearly elucidated.

\section{Acknowledgements}

Thanks to the Agency for Community Testing Services and the Florida Department of Health.

\section{REFERENCES}

[1] J. A. Jaffe and P. L. Kimmel, "Chronic Nephropathies of Cocaine and Heroin Abuse: A Critical Review," Clinical Journal of the American Society of Nephrology, Vol. 1, No. 4, 2006, pp. 655-667. doi:10.2215/CJN.00300106

[2] S. Aslibekyan, E. B. Levitan and M. A. Mittleman, "Prevalent Cocaine Use and Myocardial Infarction," American Journal of Cardiology, Vol. 102, No. 8, 2008, pp. 966-969. doi:10.1016/j.amjcard.2008.06.016

[3] K. D. Meyer and L. Zhang, "Short- and Long-Term Adverse Effects of Cocaine Abuse during Pregnancy on the Heart Development," Therapeutic Advances in Cardiovascular Disease, Vol. 3, No. 1, 2009, pp. 7-16. doi: $10.1177 / 1753944708099877$

[4] R. J. Devlin and J. A. Henry, "Clinical Review: Major Consequences of Illicit Drug Consumption," Critical Care, Vol. 12, No. 1, 2008, p. 202. doi:10.1186/cc6166

[5] C. S. Restrepo, C. A. Rojas, S. Martinez, R. Riascos, A. Marmol-Velez, J. Carrillo, et al., "Cardiovascular Complications of Cocaine: Imaging Findings," Emergency Radiology, Vol. 16, No. 1, 2009, pp. 11-19. doi:10.1007/s10140-008-0762-X

[6] K. B. Keller and L. Lemberg, "The Cocaine-Abused Heart," American Journal of Critical Care, Vol. 12, No. 6, 2003, pp. 562-566.

[7] E. Y. Plotnikov, A. A. Chupyrkina, I. B. Pevzner, N. K. Isaev and D. B. Zorov, "Myoglobin Causes Oxidative 
Stress, Increase of No Production and Dysfunction of Kidney's Mitochondria," Biochimica et Biophysica Acta, Vol. 1792, No. 8, 2009, pp. 796-803. doi:10.1016/j.bbadis.2009.06.005

[8] R. A. Kloner and S. H. Rezkalla, "Cocaine and the Heart," The New England Journal of Medicine, Vol. 348, No. 6, 2003, pp. 487-488. doi:10.1056/NEJMp020174

[9] SAMSHA, "Results from the 2008 National Survey on Drug Use and Health: National Findings," Office of Applied Studies, Rockville, 2009

[10] B. Ostadal, I. Netuka, J. Maly, J. Besik and I. Ostadalova, "Gender Differences in Cardiac Ischemic Injury and Protection-Experimental Aspects," Experimental Biology and Medicine, Vol. 234, No. 9, 2009, pp. 1011-1019. doi:10.3181/0812-MR-362

[11] A. A. Quyyumi, "Women and Ischemic Heart Disease: Pathophysiologic Implications from the Women's Ischemia Syndrome Evaluation (WISE) Study and Future Research Steps," Journal of the American College of Cardiology, Vol. 47, No. 3S, 2006, pp. S66-S71. doi:10.1016/j.jacc.2004.11.075

[12] R. A. Kloner, S. Hale, K. Alker and S. Rezkalla, "The Effects of Acute and Chronic Cocaine Use on the Heart," Circulation, Vol. 85, No. 2, 1992, pp. 407-419. doi:10.1161/01.CIR.85.2.407

[13] H. F. Poon, L. Abdullah, M. A. Mullan, M. J. Mullan and F. C. Crawford, "Cocaine-Induced Oxidative Stress Precedes Cell Death in Human Neuronal Progenitor Cells," Neurochemistry International, Vol. 50, No. 1, 2007, pp. 69-73. doi:10.1016/j.neuint.2006.06.012

[14] I. S. Richards, "Health Effects of Illicit Cocaine Use," Pulmonary and Critical Care Update American College of Chest Physicians, Vol. 7, No. 2, 1991, pp. 1-7.

[15] J. R. Richards, "Rhabdomyolysis and Drugs of Abuse," Journal of Emergency Medicine, Vol. 19, No. 1, 2000, pp. 51-56. doi:10.1016/S0736-4679(00)00180-3

[16] T. Pisitkun, R. Johnstone and M. A. Knepper, "Discovery of Urinary Biomarkers," Molecular \& Cellular Proteomics, Vol. 5, No. 10, 2006, pp. 1760-1771.

\section{doi:10.1074/mcp.R600004-MCP200}

[17] D. Seger, "Cocaine, Metamfetamine, and MDMA Abuse: The Role and Clinical Importance of Neuroadaptation," Clinical Toxicology (Philadelphia), Vol. 48, No. 7, 2010, pp. 695-708. doi:10.3109/15563650.2010.516263

[18] G. Silvestrelli, F. Corea, S. Micheli and A. Lanari, "Clinical Pharmacology and Vascular Risk," Open Neurology Journal, Vol. 4, 2010, pp. 64-72.

[19] S. B. Karch, "Karch's Pathology of Drug Abuse," 4th Edition, CRC/Taylor \& Francis, Boca Raton, 2009.

[20] A. I. Qureshi, M. F. Suri, L. R. Guterman and L. N. Hopkins, "Cocaine Use and the Likelihood of Nonfatal Myocardial Infarction and Stroke: Data from the Third National Health and Nutrition Examination Survey," Circulation, Vol. 103, No. 4, 2001, pp. 502-506. doi:10.1161/01.CIR.103.4.502

[21] P. M. Johnson and P. J. Kenny, "Dopamine D2 Receptors in Addiction-Like Reward Dysfunction and Compulsive Eating in Obese Rats," Nature Neuroscience, Vol. 13, No. 5, 2010, pp. 635-641. doi:10.1038/nn.2519

[22] C. W. Callaway and R. F. Clark, "Hyperthermia in Psychostimulant Overdose," Annals of Emergency Medicine, Vol. 24, No. 1, 1994, pp. 68-76. doi:10.1016/S0196-0644(94)70165-2

[23] D. Roth, F. J. Alarcon, J. A. Fernandez, R. A. Preston and J. J. Bourgoignie, "Acute Rhabdomyolysis Associated with Cocaine Intoxication," The New England Journal of Medicine, Vol. 319, No. 11, 1988, pp. 673-677. doi:10.1056/NEJM198809153191103

[24] R. J. de Winter, R. W. Koster, A. Sturk and G. T. Sanders, "Value of Myoglobin, Troponin T, and CK-MB Mass in Ruling Out an Acute Myocardial Infarction in the Emergency Room," Circulation, Vol. 92, No. 12, 1995, pp. 3401-3407. doi:10.1161/01.CIR.92.12.3401

[25] M. P. Hudson, R. H. Christenson, L. K. Newby, A. L. Kaplan and E. M. Ohman, "Cardiac Markers: Point of Care Testing," Clinica Chimica Acta, Vol. 284, No. 2, 1999, pp. 223-237. doi:10.1016/S0009-8981(99)00083-2 